\title{
Risk Factors and Outcomes of Umbilical Cord Prolapse: Evaluation of 94 Cases
}

\author{
Mehmet Sukru BUDAK¹, Sedat AKGOL ${ }^{1}$ \\ Diyarbakir, Turkey
}

\begin{abstract}
OBJECTIVE: The aim of this study was to evaluate the risk factors and outcomes of umbilical cord prolapse.

STUDY DESIGN: In this descriptive retrospective study, 94 cases of umbilical cord prolapse between January 2013 and December 2014 in our department were analyzed.

RESULTS: 45166 births occurred in our hospital during the study period, and the prevalence of umbilical cord prolapse was $2.08(n=94)$ per 1000 live births, and the perinatal mortality rate was $1.1 \%$. In all pregnant women, the delivery had been performed by emergent caesarean section. The average age, gravida, parity and gestational week of pregnant women were $29.11 \pm 6.17,3.69 \pm 2.48,2.69 \pm 2.48$ and $37.61 \pm 3.17$, respectively. Singleton pregnancies were $95.7 \%(n=90)$ of all pregnancies and twin pregnancies were $4.3 \%(n=4)$. Presentation of the cases were vertex, breech or transverse at $75.5 \%(n=71)$, $16 \%(n=15)$ and $8.5 \%(n=8)$ of all cases respectively. Polyhydramnios complicated $13.8 \%(n=13)$ of all cases and average birth weight was $3138.62 \pm 759.89$ grams. $16 \%(n=15)$ of the cases had a birthweight lesser than $2500 \mathrm{gr}$. $1^{\text {st }}$ and $5^{\text {th }}$ minute APGAR scores were $6.89 \pm 2.05$ and $8.69 \pm 1.39$, respectively. The time period between the diagnosis and delivery was demonstrated as $8.24 \pm 1.22$ minutes.
\end{abstract}

CONCLUSION: Breech presentation, polyhydramnios, multiple pregnancies and low birth weight are risk factors for umbilical cord prolapse. Shortening the time interval between diagnosis and delivery significantly reduces perinatal mortality. It can be provided at clinics that presenting the appropriate infrastructures for rapid intervention.

Keywords: Emergency caesarean section, Perinatal mortality, Umbilical cord prolapse

Gynecol Obstet Reprod Med 2019;25(1):1-3

\section{Introduction}

Umbilical cord prolapse is one of the rare obstetrics emergency and has been defined as the descent of the umbilical cord through the cervix (1-2). The prevalence has been shown to be between 1.4 and 6.2 per 1000 pregnancies in the literature (3-

${ }^{1}$ Health Sciences University, Diyarbakir Gazi Yasargil Training and Research Hospital, Department of Obstetrics and Gynecology Diyarbakir, Turkey

Address of Correspondence: Mehmet Sukru Budak

Health Sciences University, Diyarbakir

Gazi Yasargil Training and Research

Hospital, Department of Obstetrics and

Gynecology, 21090 Baglar

Diyarbakir, Turkey

dr.budakms@gmail.com

Submitted for Publication: $\quad 28.02 .2018$

Accepted for Publication: $\quad 18.04 .2018$

ORCID IDs of the authors:

MS.B.: 0000-0001-7328-4188, S.A.: 0000-0001-8609-3049

\begin{tabular}{|c|c|}
\hline Quick Response Code: & Access this article online \\
\cline { 2 - 2 } & Website: www.gorm.com.tr \\
\cline { 2 - 2 } & e- mail: info@gorm.com.tr \\
\cline { 2 - 3 } & DOI:10.201613/GORM.2018.783 \\
\hline
\end{tabular}

How to cite this article: Budak MS and Akgol S. Risk Factors and Outcomes of Umbilical Cord Prolapse: Evaluation of 94 Cases. Gynecol Obstet Reprod Med 2019;25(1):1-3
5). If rapid diagnosis is not possible, perinatal mortality varies between 3.5 and 19\% (6). Two types of umbilical cord prolapse have been defined: overt and occult. In the overt type, the cord is between the vulvas or in the vagina. In the occult type, the cord is caudal to the presented part and can be detected only upon cervix during digital examination. Several risk factors (such as multiparity, prematurity, breech presentation, multiple pregnancies, polyhydramnios, artificial rupture of membranes, low birth weight, etc.) are associated with umbilical cord prolapse (3). However, it is difficult to predict pregnancies that may get complicated by umbilical cord prolapse (7). Both rapid diagnosis and the emergent delivery are crucial for the reduction of perinatal mortality and morbidity (8-9).

In this study, we aimed to evaluate the risk factors and outcomes of umbilical cord prolapse.

\section{Material and Method}

This descriptive retrospective study was approved by the local ethics committee (02.02.2018-18). In this study, 94 cases those were subjected to umbilical cord prolapse between January 2013 and December 2014 in the Health Sciences University Diyarbakir Gazi Yasargil Training and Research Hospital have been analyzed. Information about pregnancies 
with umbilical cord prolapse was obtained by reviewing the hospital medical records. In compliance with ethical standards, anonymous data were generated for statistical analysis.

The ages and parities of the patients, gestational weeks, presentation of the fetuses, whether the pregnancy is a singleton or twin pregnancy, the time period between diagnosis and delivery, type of delivery, birth weight and $1^{\text {st }}$ and $5^{\text {th }}$ minute APGAR scores have been recorded for the pregnant women and the obtained data were compared with the literature. The exclusion criteria were the pregnancies with umbilical cord prolapse and without any fetal cardiac activity those were determined in the obstetric ultrasound.

\section{Statistical analysis}

IBM SPSS Statistics 22 (IBM SPSS, Chicago) software has been used for the statistical analyses. Descriptive statistical methods (average, standard deviation, frequency) was used for the analysis of the data.

\section{Results}

During the study period, the total number of births was 45166, and the prevalence of umbilical cord prolapse was 2.08 per 1000 births. Perinatal mortality rate was $1.1 \%(n=1)$. In all cases, the delivery route was emergency caesarean section.

Distribution of obstetric and neonatal outcomes and characteristics of pregnant women that are complicated with umbilical cord prolapse are presented in table 1 . The average age of the patients was $29.11 \pm 6.17$ years. The average gravidity, parity, gestational week at birth were found to be $3.69 \pm 2.48$ (median 3), 2.69 \pm 2.48 (median 2) and 37.61 \pm 3.17 , respectively. The time period between diagnosis and delivery was $8.24 \pm 1.22$ minutes. $1^{\text {st }}$ and $5^{\text {th }}$ minute APGAR scores were $6.89 \pm 2.05$ and $8.69 \pm 1.39$, respectively. Average birth weight was $3138.62 \pm 759.89$ grams. $95.7 \%(n=90)$ of all cases were singleton pregnancies while $4.3 \%(n=4)$ were twin pregnancies. Presentation of the cases was vertex, breech or transverse at $75.5 \%(\mathrm{n}=71), 16 \%(\mathrm{n}=15)$ and $8.5 \%(\mathrm{n}=8)$ of the cases, re-

Table 1: Distribution of obstetric and neonatal outcomes and characteristics of pregnant women that are complicated with umbilical cord prolapse

\begin{tabular}{|c|c|}
\hline & $\begin{array}{l}\text { Umbilical cord prolapse } \\
\qquad \mathrm{n}=94\end{array}$ \\
\hline Age $(y)$, ave. $\pm S D,(\min -\max )$ & $29.11 \pm 6.17(16-43)$ \\
\hline Gravida, ave..SD, (min-max) & $3.69 \pm 2.48(1-12)$ \\
\hline Parity, ave $\pm S D$, (min-max) & $2.69 \pm 2.48(0-11)$ \\
\hline Gestational week, ave $\pm S D$, (min-max) & $37.61 \pm 3.17(27-41)$ \\
\hline Time between diagnosis and delivery (minute), ave..SD, (min-max) & $8.24 \pm 1.22(6-13)$ \\
\hline $1^{\text {st }}$ minute Apgar score, ave $\pm S D$, (min-max) & $6.89 \pm 2.05(1-10)$ \\
\hline $5^{\text {th }}$ minute Apgar score, ave. $\pm S D$, (min-max) & $8.69 \pm 1.39(4-10)$ \\
\hline Birth weight (gr), ave. $\pm S D$, (min-max) & $3138.62 \pm 759.89(720-4500)$ \\
\hline \multicolumn{2}{|l|}{ Pregnancy, n (\%) } \\
\hline -singleton & $90(95.7 \%)$ \\
\hline -twin & $4(4.3 \%)$ \\
\hline \multicolumn{2}{|l|}{ Fetal Presentation, n (\%) } \\
\hline -vertex & $71(75.5 \%)$ \\
\hline - breech & $15(16.0 \%)$ \\
\hline - transverse & $8(8.5 \%)$ \\
\hline \multicolumn{2}{|l|}{ Type of delivery, $\mathrm{n}(\%)$} \\
\hline - caesarean & $94(100 \%)$ \\
\hline \multicolumn{2}{|l|}{ Gestational week, n (\%) } \\
\hline$-<37$ weeks & $22(23.4 \%)$ \\
\hline$-\geq 37$ weeks & $72(76.6 \%)$ \\
\hline \multicolumn{2}{|l|}{ Birth weight, n (\%) } \\
\hline$-<2500 \mathrm{gr}$ & $15(16 \%)$ \\
\hline$-\geq 2500 \mathrm{gr}$ & $79(84 \%)$ \\
\hline \multicolumn{2}{|l|}{ Amniotic fluid, n (\%) } \\
\hline - Normal & $81(86.2 \%)$ \\
\hline - Polyhydramnios & $13(13.8 \%)$ \\
\hline
\end{tabular}

Ave: Average, Min: Minimum, Max: Maximum, Gr: Gram, Y: Year 
spectively. During the diagnosis, the gestational week was lower than 37 weeks in $23.4 \%(n=22)$, and the remaining $76.6 \%(n=72)$ was over 37 weeks. For $16 \%$ of the cases $(n=15)$ the birth weight was under 2500 grams, and the remaining $84 \%(n=79)$ was over 2500 grams. For $86.2 \%(n=81)$ of the pregnant women, the amniotic fluid was normal, however, the remaining $13.8 \%(n=13)$ was found to be complicated with polyhydramnios.

\section{Discussion}

Despite the fact that umbilical cord prolapse is a rare obstetrics emergency and risk factors are well known, it is difficult to predict it. It was reported that sudden, severe and prolonged decelerations after normal fetal heartbeats can be the first sign of umbilical cord prolapse (10).

Gungorduk et al. had determined the prevalence as 0.95 per 1000 deliveries, and it was reported 1.4 in the study by Khan et al., Faiz et al. had reported mildly elevated rates as 1.99 than previous studies $(11,12,13)$. The rate obtained from our study was 2.08 and it was similar to literature, but higher than the results of the studies mentioned above (11-13).

When considering the existing risk factors in our study, the rate of breech presentation, polyhydramnios, multiple pregnancies and low birth weight was $16 \%, 13.8 \%, 4.3 \%$ and 16 $\%$ respectively and these results were similar to the other studies $(11,14-16)$.

The perinatal mortality rates vary between 3.5 and $19 \%$ in literature (4). The most important factor for perinatal mortality was determined as the time period between diagnosis and delivery. In our study, the perinatal mortality rate was $1.1 \%$ and the average time period between diagnosis and delivery was 8.24 minutes. In our study, the perinatal mortality rate is lower than those mentioned in the literature and the time elapsed between diagnosis and delivery is quite short. This shorter time period is related to our delivery room facilities such as continuous fetal monitoring for all of the pregnant patients, and presence of 7/24 working active surgery and anesthesia team in the delivery room. Esinler et al. had obtained $8.3 \pm 3.1$ minutes' time interval between diagnosis and delivery with the same delivery room facilities and it was similar to our results (14).

Small number of cases, retrospective design of the study and lack of a control group may be considered as limitations of our study.

In conclusion, umbilical cord prolapse is a rare obstetrics emergency. Breech presentation, polyhydramnios, multiple pregnancies and low birth weights are the risk factors for umbilical cord prolapse. Shortening the time interval between diagnosis and delivery significantly reduces perinatal mortality. It can be provided at clinics that presenting the appropriate infrastructures for rapid intervention.

: We have no conflict of interest to declare.

Funding: None

\section{References}

1. Murphy DJ, MacKenzie IZ. The mortality and morbidity associated with umbilical cord prolapse. Br J Obstet Gynaecol. 1995;102(10):826-30.

2. Lin MG. Umbilical cord prolapse. Obstet Gynecol Surv. 2006;61(4):269-77.

3. Gabbay-Benziv R, Maman M, Wiznitzer A, Linder N, Yogev Y. Umbilical cord prolapse during delivery - risk factors and pregnancy outcome: a single center experience. J Matern Fetal Neonatal Med. 2014;27(1):14-7.

4. Holbrook BD, Phelan ST. Umbilical cord prolapse. Obstet Gynecol Clin North Am. 2013;40(1):1-14.

5. Yamada T, Kataoka S, Takeda M, Kojima T, Yamada T, Morikawa M, et al. Umbilical cord presentation after use of a trans-cervical balloon catheter. J Obstet Gynaecol Res. 2013;39(3):658-62.

6. Mesleh R, Sultan M, Sabagh T, Algwiser A. Umbilical cord prolapse. J Obstet Gynecol. 1993;13(1):24-8.

7. Koonings PP, Paul RH, Campbell K. Umbilical cord prolapse. A contemporary look. J Reprod Med. 1990;35(7): 690-2.

8. Katz Z, Lancet M, Borenstein R. Management of labor with umbilical cord prolapse. Am J Obstet Gynecol. 1982; 142(2):239-41.

9. Levy H, Meier PR, Makowski EL. Umbilical cord prolapse. Obstet Gynecol. 1984;64(4):499-502.

10. Sheiner E, Hadar A, Hallak M, Katz M, Mazor M, Shoham-Vardi I. Clinical significance of fetal heart rate tracings during the second stage of labor. Obstet Gynecol. 2001;97(5):747-52

11. Gungorduk K, Yildirim G, Olgac Y, Tekirdag AI, Ark HC. Umbilical cord prolapse: Risk factors and perinatal outcomes. Turk J Obstet Gynecol. 2008;5(2):94-8.

12. Khan RS, Naru T, Nizami F. Umbilical cord prolapse--a review of diagnosis to delivery interval on perinatal and maternal outcome. J Pak Med Assoc. 2007;57(10):487-91.

13. Faiz SA, Habib FA, Sporrong BG, Khalil NA. Results of delivery in umbilical cord prolapse. Saudi Med J. 2003;24(7):754-57

14. Esinler I, Beishenova D, Akyol D, Onderoglu L. Umbilical cord prolapsus: Maternal and fetal results. Turk J Obstet Gynecol. 2005;2(3):192-6.

15. Kahana B, Sheiner E, Levy A, Lazer S, Mazor M. Umbilical cord prolapse and perinatal outcomes. Int J Gynaecol Obstet. 2004;84(2):127-32.

16. Murphy DJ, MacKenzie IZ. The mortality and morbidity associated with umbilical cord prolapse. $\mathrm{Br} \mathrm{J}$ Obstet Gynaecol. 1995;102(10):826-30. 